\title{
Effects of low-dose ionizing radiation on $\alpha, \beta$-globulins solutions studied by DSC
}

\author{
Anna Michnik • Kinga Polaczek-Grelik • \\ Piotr Leśniak · Zofia Drzazga
}

Received: 23 February 2012 / Accepted: 4 September 2012/Published online: 29 September 2012

(C) The Author(s) 2012. This article is published with open access at Springerlink.com

\begin{abstract}
An attempt has been made to detect the effect of a small dose of ionizing radiation on the course of $\alpha, \beta$-globulin thermal denaturation in aqueous solutions. Doses of 0.1 and 1.8 Gy have been delivered using $\gamma$-rays emitted by ${ }^{60} \mathrm{Co}$ isotope while doses of 10 and 100 Gy have been supplied by X-rays produced by linear accelerator. The highest dose has visibly changed DSC curve of protein solution while the changes due to lower doses are hardly detectable. Although very weak, the irradiation effect found has been dose dependent. The results suggest that the influence of ionizing radiation on globulins solution is bigger when the dose rate is lower at given dose. The opposite direction of differences between irradiated and control samples for fresh and stored protein solutions suggests various characters of changes in initial and later period of sample aging. This may be an important reason for difficulties in an investigation of the effect of ionizing radiation on protein solution, especially for low doses delivered very slowly.
\end{abstract}

Keywords $\alpha, \beta$-Globulins - Differential scanning calorimetry · Gamma and X-irradiation .

Protein denaturation · Protein aging

\section{Introduction}

The benefits and risks of practices that use ionizing radiation in research, medicine, industry, and energy production are

A. Michnik $(\bowtie) \cdot$ K. Polaczek-Grelik $\cdot$ P. Leśniak $\cdot$ Z. Drzazga Department of Medical Physics, A. Chełkowski Institute of Physics, University of Silesia, ul. Uniwersytecka 4, 40-007 Katowice, Poland

e-mail: anna.michnik@us.edu.pl nowadays widely discussed. The biological and health effects from exposure to high doses of ionizing radiation have been well documented [1]. In practice doses, from 50 Gy up to kilograys are widely used, e.g., in radiotherapy treatment, in the manufacture of products derived from plasma (dose of $45 \mathrm{kGy}$ inactivates all known blood-borne viruses), as well as in sterilization of the medical equipment and food products. The effects of irradiation at high doses of tens kGy on molecular, physicochemical, and functional properties of various proteins have been widely reviewed [2-10].

A growing interest can be observed in studies concerning effects from exposure to low-dose radiation on biological systems. Recent evidence suggests that low doses of ionizing radiation might have a beneficial effect as well as be a harmful agent, depending on the biological structure where the dose is deposited and on the stage of its development. The distinct effect of low- (below 0.5 Gy) versus high-dose radiation on cell proliferation has been demonstrated [11]. Description of stimulation of the repair mechanisms and the reduction of cancer incidence in a population irradiated with doses around $0.1 \mathrm{~Gy}$ can be found in literature [12].

A number of studies has been reviewed that demonstrate an adaptive response following low doses of ionizing radiation [13-15]. The opposite direction of cellular and molecular changes induced by low (below $0.2 \mathrm{~Gy}$ ) versus high dose (above $0.5 \mathrm{~Gy}$ ) has been observed [16]. Also, the low-dose radiation research program in the Department of Energy has been aimed at understanding the outcomes of the observation of biological effects of low doses [17].

In general, research of low-dose effects is directed into two ways: (1) the understanding of the mechanisms of the cellular response to ionizing radiation together with 
the dose-rate effect which is aimed at the improvement of the effectiveness of radiation therapy as well as the epidemiological studies of the natural environment, and (2) the searching for changes in physical properties of the molecules aimed at the so-called biomolecular dosimetry, where the relation between the strength of these changes and the dose of radiation is of the particular interest.

The influence of ionizing radiation on proteins has been the subject of great attention, and different techniques have been applied to study radiation-induced modifications in proteins [9, 10]. Changes in peptide ions' abundance in serum after radiotherapy (51-72 Gy) as well as changes in serum proteome profiles are observed and expected to have a potential prognostic and predictive value in radiation therapy $[18,19]$.

Differential scanning calorimetry (DSC) is a rapidly expanding technique in bio-life and medical sciences, more and more often applied to biological systems in recent years, e.g., [20, 21]. DSC belongs to experimental methods which enable the detection of differences between the nonirradiated and irradiated protein. In particular, a significant effect of gamma irradiation at doses of 20-30 and 2.5-3 kGy has been shown by Cieśla et al. for globulins denaturation DSC profiles. It has been also found that the changes in the protein denaturation course were bigger after irradiation performed for water suspensions, as compared to native solid state samples irradiated at the same conditions [22]. However, there are probably no reports concerning the influence of small (lower than kGy) doses irradiation on the process of protein denaturation observed with using DSC.

The aim of this DSC study was to investigate the effects of relatively low-dose ionizing radiation on human serum proteins: $\alpha, \beta$-globulins in aqueous solutions. We have been using high-sensitivity DSC to examine and compare the thermal unfolding process of irradiated and non-irradiated globulins. An attempt has been undertaken to find thermal effects due to the gamma irradiation with doses of 0.1 and $1.8 \mathrm{~Gy}$ as well as $\mathrm{X}$-irradiation with doses of 10 and $100 \mathrm{~Gy}$.

Applied dose values are important from radiotherapeutic as well as radiation protection points of view. Standard single-fraction dose used in teleradiotherapy is within the range 1.6-2 Gy, that is connected to the so-called window of opportunity at curve of survival [23], within which healthy cells have greater survival rate than cancer ones. Although extended in time, total doses in teleradiotherapy, brachytherapy, and nuclear medicine are of the order of 65-100 Gy. Doses of $100 \mathrm{~Gy}$ are also used in the preparation of antitumor vaccines for nonproliferation purposes [24].

In total or half body irradiation, when aplastic anemia, leukemias, and lymphomas are treated, total dose of maximum $10 \mathrm{~Gy}$ has been given in a single fraction to immunosuppress the patient prior to receiving the bone marrow transplant [25].

Both radiation sources used in presented study are applied in radiotherapeutic treatment. Although in most of the oncological centers cobalt ${ }^{60} \mathrm{Co}$ machines have been replaced by linear accelerators in radiotherapeutic procedures, still gamma radiation of this isotope is often treated as a reference for calibration of dosimetric equipment used in quality control of linac photon beams [26]. The radiation quality of these two sources is characterized by the value of linear energy transfer equal to $0.3 \mathrm{keV} \mu \mathrm{m}^{-1}$ [27].

\section{Experimental}

Materials and sample preparation

$\alpha, \beta$-Globulins (product G3637) from human blood were obtained from Sigma Chemical Co. Protein solution at concentration $1.5 \mathrm{mg} \mathrm{mL}^{-1}$ was prepared by dissolving the proteins in degassed water pro injection $(\mathrm{pH} \approx 6.5)$. The exact protein concentration was determined spectrophotometrically using absorption spectra recorded in the wavelength range of $200-400 \mathrm{~nm}$ on JASCO V-530 spectrophotometer using $1.0-\mathrm{cm}$-path length quartz cuvettes.

The prepared portion of solution was divided into three parts: (1) kept over the time of experiment in a refrigerator (about $4{ }^{\circ} \mathrm{C}$ ), (2) designed for irradiation, and (3) controlkept in the same conditions as sample (2) excluding the process of irradiation. The solution (1) was treated as the reference for the solution (3), while the solution (3) was the reference for the solution (2). All samples were stored at about $4{ }^{\circ} \mathrm{C}$ until further analysis. Aging of protein samples was observed for a few weeks.

\section{Irradiation experiment}

$\alpha, \beta$-Globulins solutions were exposed at ambient temperature to electromagnetic ionizing radiation resulting in absorbed dose of $0.1,1.8,10$, and $100 \mathrm{~Gy}$. Doses of 0.1 and 1.8 Gy were delivered using $\gamma$-rays emitted by ${ }^{60} \mathrm{Co}$ isotope with the average energy of $1.25 \mathrm{MeV}$. Due to limited activity of the source, dose rates were 0.1 and $0.4 \mathrm{mGy} \mathrm{min}^{-1}$, respectively. The distance of ${ }^{60} \mathrm{Co}$ exposure was varied from 1 to $4 \mathrm{~cm}$ to maintain similar irradiation time (about 70 h). Experiments for individual doses were repeated three times.

Doses of 10 and 100 Gy were supplied by X-rays produced by linear accelerator working at the nominal potential of $6 \mathrm{MV}$. Produced Bremsstrahlung radiation is characterized by a continuous photon spectrum up to $6 \mathrm{MeV}$ with the average energy of $1.76 \mathrm{MeV}$ [27]. In order to provide uniformity of dose distribution throughout the whole sample, two opposite X-ray beams were directed 
perpendicular to the longer axis of the flask containing the solution. In each of these two fractions, half of the planned dose was delivered. High-dose rate (HDR) of $1.7 \mathrm{~Gy} \mathrm{~min}^{-1}$ and low-dose rate (LDR) of $0.6 \mathrm{~Gy} \mathrm{~min}^{-1}$ were applied.

Both radiation types used are of the same nature and have similar/comparable average energies, but applied $\mathrm{X}$-ray source enables to get higher doses in reasonable time due to its better (clinically used) efficiency.

\section{DSC measurements}

DSC measurements were carried out on a VP DSC ultrasensitive microcalorimeter (MicroCal Inc., Northampton, MA) with cell volumes of $0.5 \mathrm{~mL}$. Heat capacity versus temperature profiles were obtained in the temperature range $20-100{ }^{\circ} \mathrm{C}$ at a programmed heating rate of $1 \mathrm{~K} \mathrm{~min}^{-1}$. The constant pressure of about 1.8 atm over the liquids in the cells was applied.

The calorimetric data were corrected for the instrumental baseline water-water. DSC curves were normalized for the gram concentration of protein.

\section{Results and discussion}

The thermal denaturation of human $\alpha, \beta$-globulins serum fraction

The representative DSC cures obtained for two successive scans of the one portion of $\alpha, \beta$-globulins solution are shown in Fig. 1. The complex endothermic transition corresponds to the thermal protein denaturation. It displays multiple peaks and shoulders due to contributions from the unfolding of different constituent proteins of this serum fraction. The flat 2-nd scan indicates that the denaturation process of $\alpha, \beta$-globulins in aqueous solution is irreversible. The process of thermal denaturation of $\alpha, \beta$-globulins in water ( $\mathrm{pH}$ 6.5) and in buffer ( $\mathrm{pH}$ 7.2) solution has been characterized in detail earlier [28].

The direct effect of gamma irradiation on $\alpha, \beta$-globulin solution

DSC curves shown in Figs. 2 and 3 illustrate averaged effects of $\gamma$-rays exposition at 0.1 and $1.8 \mathrm{~Gy}$ doses (delivered with very slow rates: 0.1 and $0.4 \mathrm{mGy} \mathrm{min}^{-1}$, respectively). These direct effects of irradiation with both doses are hardly visible in DSC curves. The thermal transitions for irradiated (2) and control (3) samples do not differ significantly. There are no differences in thermodynamic parameters of endothermic denaturation transition.

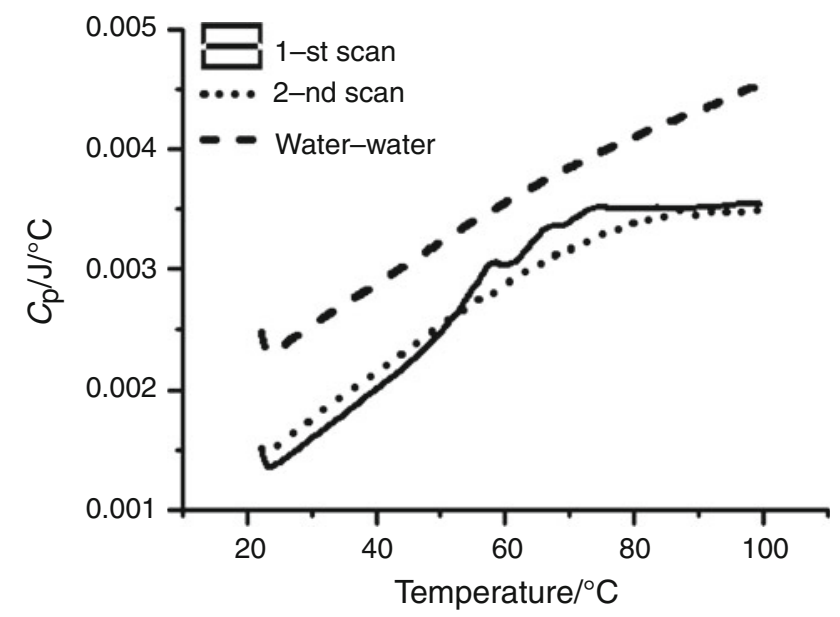

Fig. 1 The representative raw DSC data for $\alpha, \beta$-globulins solution $\left(1.5 \mathrm{mg} \mathrm{mL}^{-1}\right)$

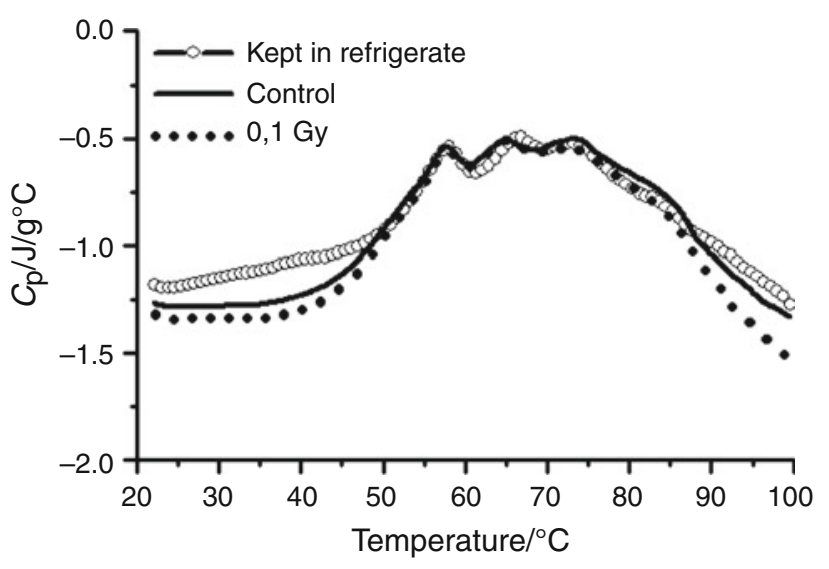

Fig. 2 The averaged DSC curves (three series of measurements) for three kinds of $\alpha, \beta$-globulin samples: (1) kept in a refrigerator (about $4{ }^{\circ} \mathrm{C}$ ) during the experiment, (2) irradiated with $0.1 \mathrm{~Gy}$ (during $70 \mathrm{~h}$ at about $23{ }^{\circ} \mathrm{C}$ ), and (3) control (kept in the same conditions as irradiated sample)

The enthalpies of denaturation $\Delta H$ for irradiated and control protein are practically the same (Table 1).

However, DSC curves for these two kinds of samples differ greatly from the curve corresponding to the freshly prepared protein solution (see Fig. 3) or to the sample (1) of $\alpha, \beta$-globulin solution kept over the time of experiment (about $70 \mathrm{~h}$ ) in a refrigerator (see Fig. 2). The differences in the slope of $C_{\mathrm{p}}$ versus $T$ and the decrease of protein heat capacity in the temperature range $20-50{ }^{\circ} \mathrm{C}$ due to the interval of time spend by samples at room temperatures during irradiation procedure are well perceptible in Figs. 2 and 3. The shape of exothermic events manifested for samples (2) and (3) in temperatures $20-50{ }^{\circ} \mathrm{C}$ is very similar. No exothermic contribution is visible in this 


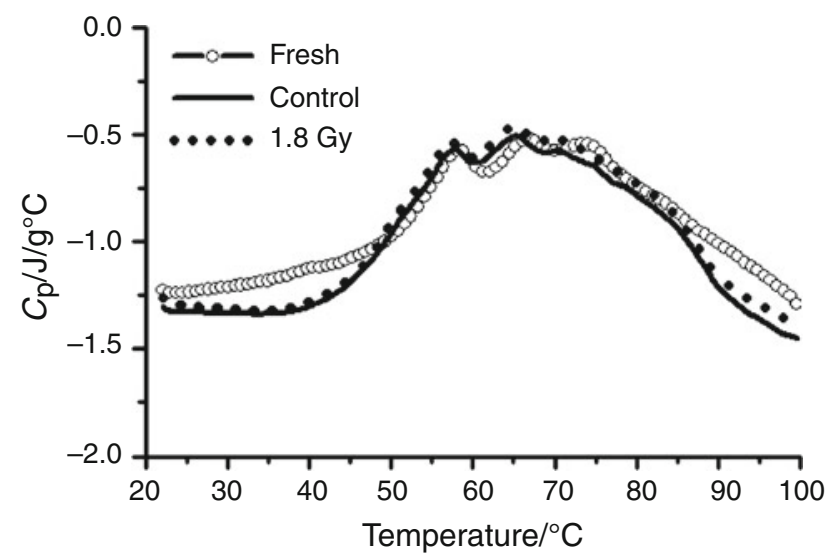

Fig. 3 The averaged DSC curves (three series of measurements) for fresh $\alpha, \beta$-globulin solution irradiated with $1.8 \mathrm{~Gy}$ (during $70 \mathrm{~h}$ at about $23{ }^{\circ} \mathrm{C}$ ) and control (kept in the same conditions as irradiated sample)

Table 1 The enthalpy changes $\Delta H / \mathrm{J} \mathrm{g}^{-1}\left( \pm 0.5 \mathrm{~J} \mathrm{~g}^{-1}\right)$ for denaturation of irradiated (i) and control (c) $\alpha, \beta$-globulins

\begin{tabular}{|c|c|c|c|c|c|c|c|c|c|}
\hline $0.1 \mathrm{c}$ & & 1.8 & & $10 \mathrm{G}$ & /LDR & $10 \mathrm{G}$ & /HDR & 100 & \\
\hline $\mathrm{i}$ & $\mathrm{c}$ & $\mathrm{i}$ & $\mathrm{c}$ & $\mathrm{i}$ & $\mathrm{c}$ & $\mathrm{i}$ & $\mathrm{c}$ & $\mathrm{i}$ & $\mathrm{c}$ \\
\hline 15.9 & 15.4 & 15.5 & 15.3 & 13.3 & 14.2 & 16.5 & 16.8 & 14.5 & 16.4 \\
\hline
\end{tabular}

temperature range for fresh and stored $\sim 70 \mathrm{~h}$ at $4{ }^{\circ} \mathrm{C}$ protein solutions.

The above results indicate that the sought effect from $\gamma$-irradiation is much smaller than that coming from $70 \mathrm{~h}$ storage of protein solution in non-cooling conditions. The heat capacity changes connected with aging of protein solution in room temperature during irradiation are greater than those induced by $\gamma$-radiation. It makes the analysis of irradiation effect difficult.

In order to clarify the problem, the time of exposition should be shortened and the effect from higher doses of $\gamma$-radiation should be recognized. However, it was not possible to receive the desired doses during the reasonable time from the applied ${ }^{60} \mathrm{Co}$ source due to its limited activity. Such experiment is planned with the new source in the future. Currently, the influence of 10 and 100 Gy coming from X-radiation on thermal unfolding of $\alpha, \beta$-globulins have been studied. The aim of this additional part of experiment, in which higher doses have been applied, was to see the course of changes connected with electromagnetic radiation from ionizing range more evidently.

The effect of X-ray exposition

Figures 4 and 5 show the effects induced by X-rays at a dose of $10 \mathrm{~Gy}$ given with HDR (1.7 Gy min ${ }^{-1}$ ) and LDR $\left(0.6 \mathrm{~Gy} \mathrm{~min}^{-1}\right)$, respectively. The slight increase of protein

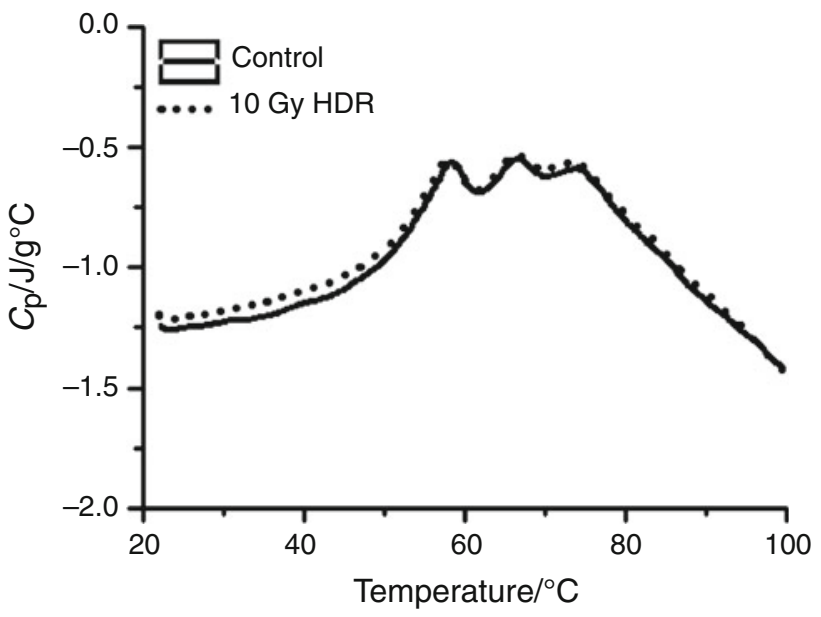

Fig. 4 DSC curves of irradiated (10 Gy, $1.7 \mathrm{~Gy} \mathrm{~min}^{-1}$ ) and control $\alpha, \beta$-globulin solution

heat capacity in the temperature range $20-50{ }^{\circ} \mathrm{C}$ can be observed as the effect of irradiation. In addition, the decrease of heat capacity above about $65{ }^{\circ} \mathrm{C}$ is visible in DSC curve but only for slowly irradiated sample. The results shown in Table 1 indicate that $\Delta H$ values for $\alpha, \beta$-globulins irradiated with 10 Gy HDR and the control one are equal. In case of the dose of 10 Gy delivered with LDR, $\Delta H$ for irradiated protein is about $0.9 \mathrm{~J} \mathrm{~g}^{-1}$ lower than for non-irradiated. Thus, the same dose of $10 \mathrm{~Gy}$ seems to modify globulins thermal transition more significantly when it is given with the lower dose rate.

Figure 6 illustrates the effect of globulin solution exposition to the dose of $100 \mathrm{~Gy}$. The comparison of Figs. 5 and 6 points that the highest studied dose (100 Gy) produced by $\mathrm{X}$-rays with rate $1.7 \mathrm{~Gy} \mathrm{~min}^{-1}$ causes very similar but more evident changes in protein DSC curve as the dose of $10 \mathrm{~Gy}$ given with the slower rate $0.6 \mathrm{~Gy} \mathrm{~min}^{-1}$.

The increase of globulins heat capacity observed in the lower temperature range after irradiation (Figs. 4, 5, 6) indicates a partial unfolding of protein under photon ionizing radiation. Such explanation may be done by analogy with the thermal unfolding. One can see in Fig. 1 that below $50{ }^{\circ} \mathrm{C}$, the DSC curve corresponding to the 2-nd scan lies above the curve representing the first heating of protein solution. This is a reflection of changed protein structure after its unfolding due to the heating to $100{ }^{\circ} \mathrm{C}$ in the first run. Conventionally, the positive changes in heat capacity during protein unfolding have been ascribed to increased exposure of hydrophobic groups to water [29]. However, the hydrophobic interactions are not the only possible source of such changes. In general, the condensed/ closely packed polypeptides-either as a result of specific folding or less-specific aggregation-have a lower heat capacity than the unraveled chain exposed to water. The positive heat capacity changes are to be expected for any 


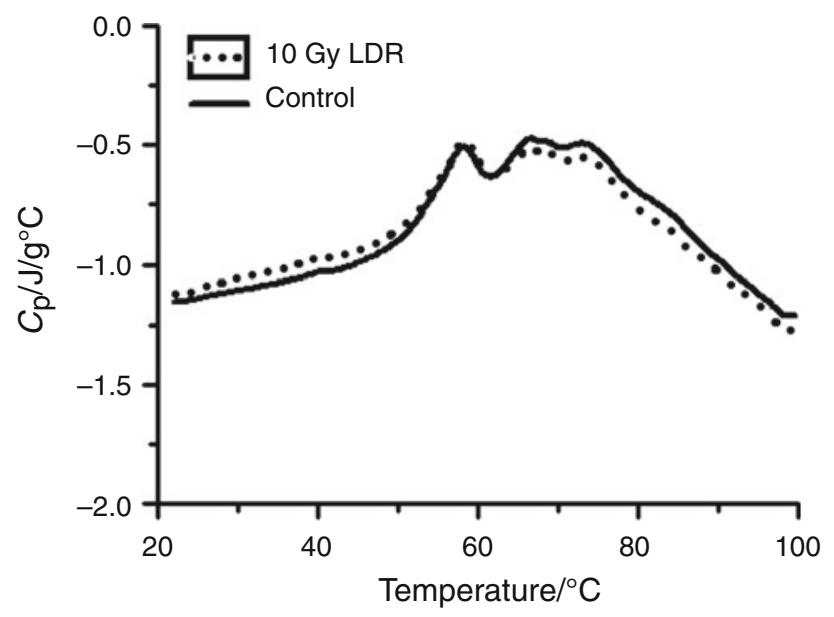

Fig. 5 DSC curves of irradiated (10 Gy, 0.6 Gy $\mathrm{min}^{-1}$ ) and control $\alpha, \beta$-globulin solution

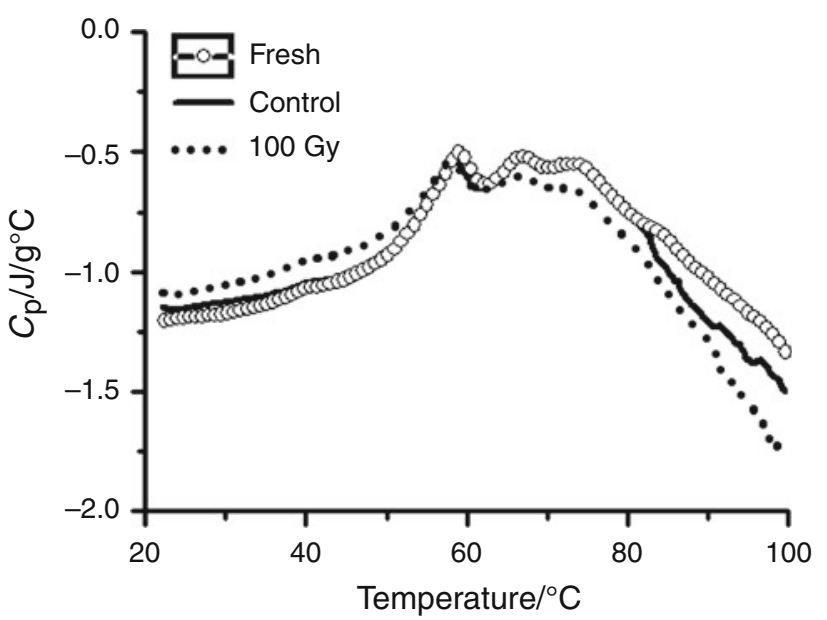

Fig. 6 DSC curves for $\alpha, \beta$-globulin solutions: fresh, irradiated with 100 Gy dose of X-rays and control

process involving the disruption of a cooperative lattice of multiple weak interactions [30, 31].

A decrease of $\mathrm{C}_{\mathrm{p}}$ at temperatures above $60{ }^{\circ} \mathrm{C}$ is well visible mainly for $\alpha, \beta$-globulin solutions exposed to $100 \mathrm{~Gy}$ dose of X-radiation. A decrease of the transition peak intensity means a decrease of the area under that peak, representing the enthalpy of protein denaturation. According to the results shown in Table $1, \Delta H$ for $\alpha, \beta$-globulins irradiated with the dose of $100 \mathrm{~Gy}$ is about $1.9 \mathrm{~J} \mathrm{~g} \mathrm{~g}^{-1}$ smaller than for non-irradiated control. It indicates a decrease of protein stability under photon ionizing radiation. The character of changes suggests that the observed endothermic transition may be modified by exothermic events such as an aggregation of protein proceeding in the higher temperature range.

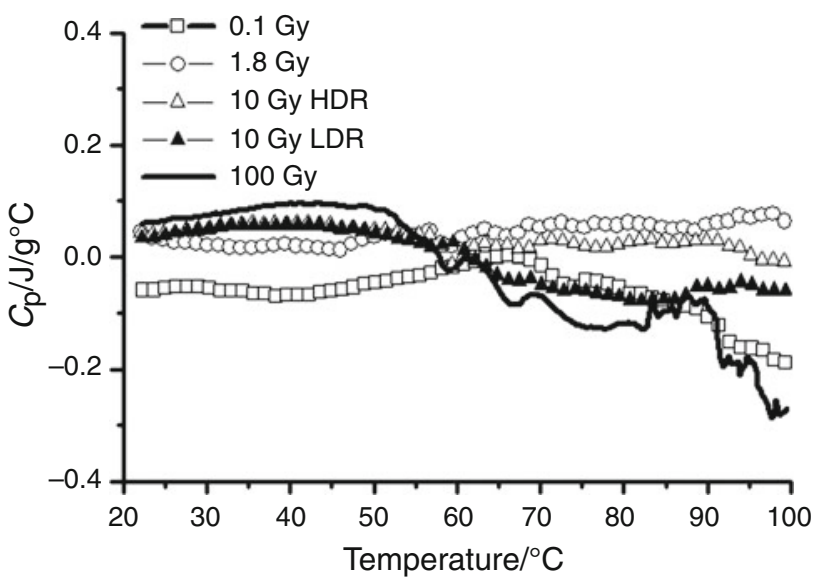

Fig. 7 Differential curves between DSC curves for irradiated (with shown doses) and control protein samples

The dependence of the effect on the dose of ionizing radiation

In Fig. 7, the differential curves obtained as the differences between DSC curves for protein samples irradiated with different doses and adequate controls are shown. All differences are relatively small. However, the results suggest the dose dependence of the effect of ionizing radiation on $\alpha, \beta$-globulins denaturation process. It is worth to notice the opposite character of the effect observed in the temperature range $20-60{ }^{\circ} \mathrm{C}$ for the smallest dose of $0.1 \mathrm{~Gy}$ in comparison with all higher doses. In this temperature range, the difference between DSC curves for irradiated with 0.1 Gy and control samples is negative; while for other doses, analogous differences are positive. The heat effects corresponding to discussed differences, calculated by integration of differential curves (shown in Fig. 7) from zero are about: $-2,1$, and $3 \mathrm{~J} \mathrm{~g}^{-1}$ for doses of $0.1,1.8$, and $100 \mathrm{~Gy}$, respectively.

The differential curves as well as matching heat effects for $10 \mathrm{~Gy}$ delivered with high-dose rate (HDR) of $1.7 \mathrm{~Gy} \mathrm{~min}^{-1}$ and low-dose rate (LDR) of $0.6 \mathrm{~Gy} \mathrm{~min}^{-1}$ are practically the same in a considered temperature range. Thus, the dose rate does not influence the protein heat capacity changes caused by a given dose in that lower temperature range. Just the opposite, in the temperature range above $60{ }^{\circ} \mathrm{C}$ significant differences occur between differential curves for $10 \mathrm{~Gy}$ dose delivered with both dose rates. It follows from the comparison of these curves that the effect of ionizing radiation on the stability of $\alpha, \beta$-globulins in aqueous solution is more pronounced when the dose rate is lower at given dose.

It is not clear from our experimental data whether low doses $(0.1$ and $1.8 \mathrm{~Gy})$ of $\gamma$-radiation cause the partial unfolding of protein structure. The results shown in Figs. 2, 3 , and 7 suggest that the answer is "no." However, the 
$\gamma$-irradiation time (about $70 \mathrm{~h}$ ) has been a more meaningful origin of protein solution changes than ionizing radiation exposition itself. Effects from both factors overlap and it is feasible that one of them is able to annul the other. So, it is necessary to know and understand the aging effect to eliminate it.

Aging of protein samples stored in a refrigerator (about $4{ }^{\circ} \mathrm{C}$ )

The reported results indicate that the recognizing of the contribution from the aging process is essential to catch the effect of low doses of ionizing radiation on protein solution. Figure 8 illustrates DSC curves for $\alpha, \beta$-globulin solutions stored in a refrigerator at about $4{ }^{\circ} \mathrm{C}$ (sample (1)) up to 8 weeks. It is likely that the process of aging for irradiated and control $\alpha, \beta$-globulins (samples (2) and (3)) has proceeded in a similar way as for the sample (1). However, it has been accelerated due to $70 \mathrm{~h}$ spent by these samples at the higher temperature (about $23{ }^{\circ} \mathrm{C}$ ) during the initial part of the experiment when the protein solution was irradiated.

The comparison of DSC curves for $\alpha, \beta$-globulin solutions stored over various periods of time (Fig. 8) indicates the complexity of changes connected with the protein aging. Taking the DSC curve for fresh sample as a reference, the opposite direction of heat capacity changes in the temperature range from 20 to about $50{ }^{\circ} \mathrm{C}$ is visible in the initial and the later stages of the aging process. Namely, for the sample stored for 1 week an increase while for the sample stored a few weeks a decrease of the protein heat capacity is observed, respectively. One can see that in the higher temperature range, the heat capacity of $\alpha, \beta$-globulins in aqueous solutions reveals the tendency to increase during a few week storage.

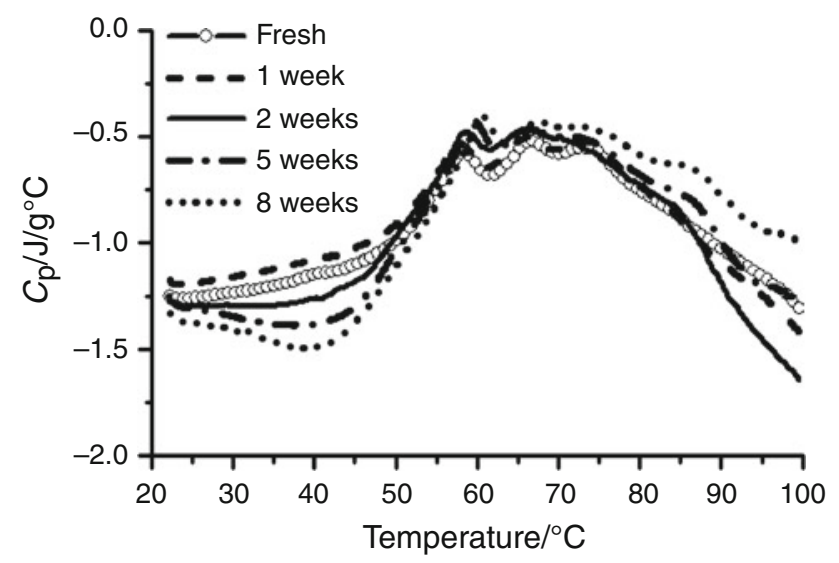

Fig. 8 The comparison of averaged normalized DSC curves for $\alpha, \beta$ globulin solutions stored over various periods of time in a refrigerator at about $4{ }^{\circ} \mathrm{C}$
It is known that the change of heat capacity of protein solution is mainly caused by the change in hydration. Hydration effects are proportional to the exposed surface areas of polar and apolar groups [32]. At room temperature, the partial heat capacity of unfolded proteins is significantly larger than that of the native protein. Therefore, an increase of $\alpha, \beta$-globulins heat capacity in the lower temperature range during a few days storage (up to 1 week) indicates the exposure of internal groups to water upon limited protein unfolding. This effect is not visible in DSC curve during longer storage of protein solution because other effects (such as an exothermic aggregation) prevail. An increase of globulin heat capacity in the higher temperature range observed for 8 -week-old solution suggests a facilitation of the unfolding process in aged protein solution.

Are there any differences in aging of irradiated and control protein samples?

The exposure to $0.1 \mathrm{~Gy} \gamma$-radiation does not change the process of $\alpha, \beta$-globulin solutions aging (data not shown). However, the dose of $1.8 \mathrm{~Gy}$ of $\gamma$-radiation seems to be effective in the acceleration of globulins solutions aging during storage. Figure 9 illustrates the differences between DSC curves for irradiated and control protein samples both stored at $4{ }^{\circ} \mathrm{C}$ up to 9 weeks.

Also, X-ray irradiation with a dose of 10 Gy delivered with low-dose rate (LDR) of $0.6 \mathrm{~Gy}^{-1} \mathrm{~min}^{-1}$ alters the process of globulins aging. Figure 10 shows DSC curves for stored 20 days control and irradiated samples in comparison with the curves for the fresh protein solution and the curves obtained shortly after the irradiation process (1-day samples). The differences between DSC curves for irradiated (10 Gy, LDR) and control one and 20-day-old globulin samples are presented in Fig. 11. The opposite

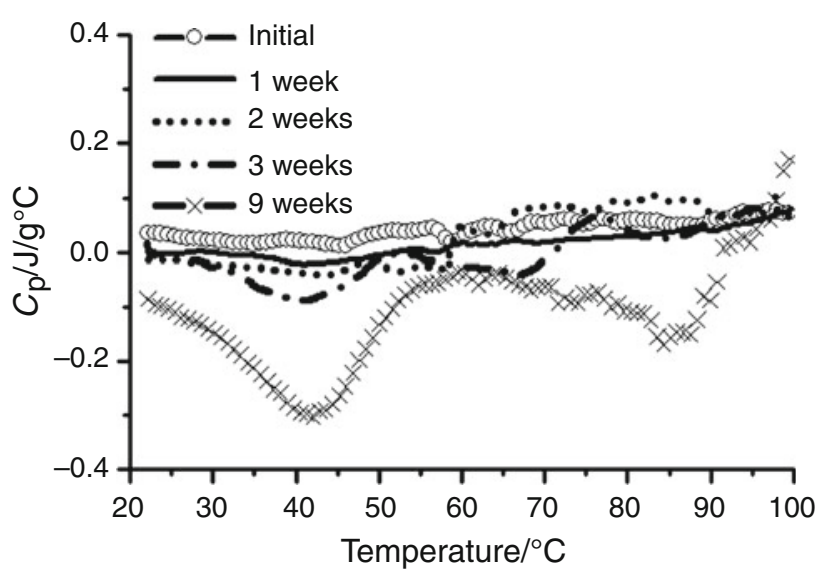

Fig. 9 Differences between DSC curves for irradiated (1.8 Gy) and control protein samples stored at $4{ }^{\circ} \mathrm{C}$ up to 9 weeks 


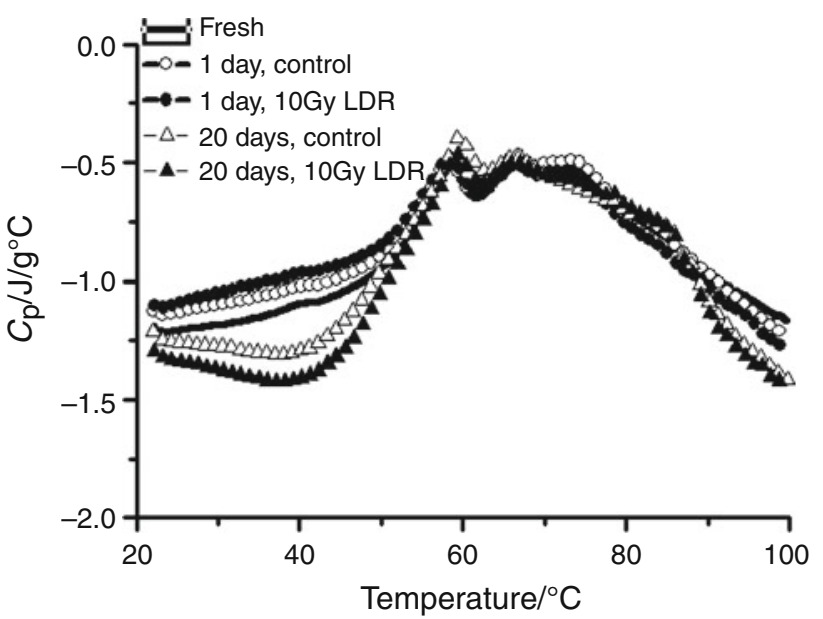

Fig. 10 DSC curves for fresh and stored (at $4{ }^{\circ} \mathrm{C}$ ) $\alpha, \beta$-globulin solutions: irradiated (10 Gy, LDR) and control

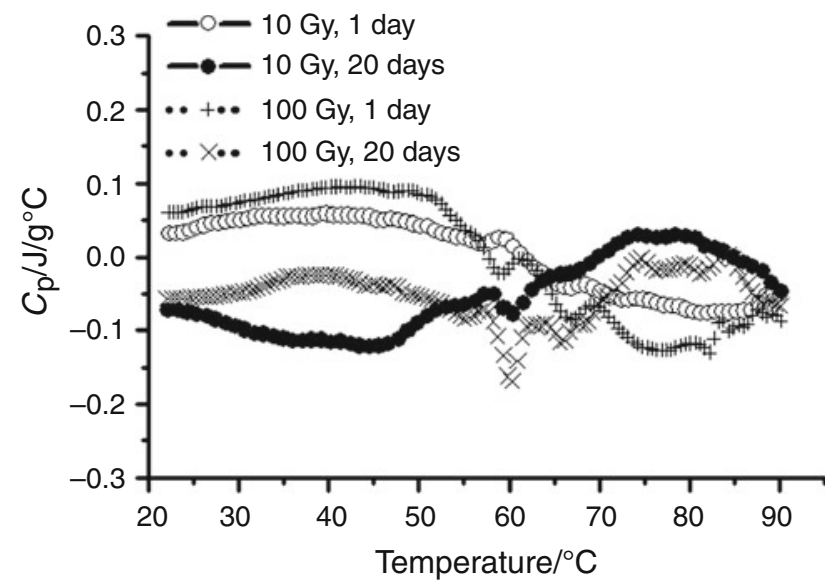

Fig. 11 Differences between DSC curves for irradiated (10 Gy, LDR; $100 \mathrm{~Gy}, \mathrm{HDR}$ ) and control protein samples: 1-day and stored for 20 days at $4{ }^{\circ} \mathrm{C}$

direction of these differences for one and 20-days stored samples is well visible in both figures. Thus, it may be concluded that $10 \mathrm{~Gy}$ (LDR) irradiation accelerates two various processes of globulins aging in the initial (1 day) and later (20 days) stage of storage. In addition, the opposite character of differences appears in the lower and higher temperature range of DSC scan (Fig. 11).

It follows from DSC results obtained for the lower temperature range that $10 \mathrm{~Gy}$ (LDR) exposition intensifies the unfolding and aggregation of fresh and aged globulins, respectively. In the higher temperature range it seems to be inversely. However, the interpretation of these data is probably more complex.

It is intriguing that the dose of $10 \mathrm{~Gy}$ delivered with the high-dose rate (HDR) of $1.7 \mathrm{~Gy} \mathrm{~min}^{-1}$ does not influence the aging of protein solution significantly (data not shown). The dose of $100 \mathrm{~Gy}$ given with the same dose rate also leads to relatively small differences between aging of irradiated and control samples (Fig. 11). Particularly, in the lower temperature range these differences are smaller than for the dose of 10 Gy delivered with LDR.

\section{Conclusions}

The applied doses of $0.1,1.8,10$, and $100 \mathrm{~Gy}$, important from radiotherapeutic as well as radiation protection points of view, do not change significantly DSC profiles of $\alpha, \beta$-globulin aqueous solution. The direct effects of $\gamma$-irradiation with dose of $0.1 \mathrm{~Gy}$ as well as $1.8 \mathrm{~Gy}$ delivered

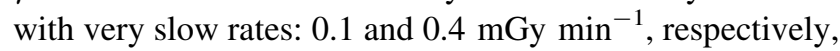
seem to be very weak because they are hardly visible in DSC curves. Nevertheless, they may be overlapped by "room temperature effect." The effect of exposition to X-rays resulting in absorbed dose of $100 \mathrm{~Gy}$ is well visible. The changes in DSC curves caused by 10 Gy dose of X-rays are similar in character but smaller than those for $100 \mathrm{~Gy}$. More clear differences between irradiated and control samples have been observed when the dose of 10 Gy was delivered slowly.

Dose rate seems to be an important variable in determining the biological response of irradiated tumors and normal tissues. The findings from the cell experiment made by Rogoliński et al. [33] confirm the dose-rate effect on a biological damage. The higher degree of damage has been observed for lower dose rates.

The opposite character of the weak irradiation effects observed for the lowest dose and all higher studied doses in the temperature range $20-60{ }^{\circ} \mathrm{C}$ suggests that the dose of $0.1 \mathrm{~Gy}$ does not cause the protein unfolding, while under the higher doses the unfolding is present or made easier.

The opposite direction of differences between irradiated and control samples for fresh and stored protein solutions suggests various character of changes in the initial and later period of sample aging. This may be an important reason for difficulties in an investigation of the effect of ionizing radiation on protein solution, especially at low doses.

In conclusion, our study has demonstrated that it is difficult to show clearly the effect coming from doses below 100 Gy on $\alpha, \beta$-globulin solutions using DSC method. This method allows to suggest undoubtedly the direction of changes caused by considered doses of electromagnetic ionizing radiation. However, the evaluation of the effects observed in this study was possible in a qualitative way only. Quantitative interpretation of protein heat capacity changes and related effects under low doses of ionizing radiation remains a challenge. 
Acknowledgements Authors are grateful to the medical physicists from Radiotherapy Department of S. Leszczyński Memorial Hospital in Katowice, Poland for the opportunity to use the linear accelerator in the presented study. Special thanks to Aleksander Ciba for conducting the irradiation procedure.

Open Access This article is distributed under the terms of the Creative Commons Attribution License which permits any use, distribution, and reproduction in any medium, provided the original author(s) and the source are credited.

\section{References}

1. Wrixon AD, Barraclough I, Clark MJ. Radiation, people and the environment: a broad view of ionizing radiation, its effects and uses, as well as the measures in place to use it safely. Diane Publishing Company: IAEA; 2004.

2. Le Maire M, Thauvette TL, de Foresta TB, Viel A, Beauregardt G, Potier M. Effects of ionizing radiations on proteins. Evidence of non-random fragmentations and a caution in the use of the method for determination of molecular mass. Biochem $\mathrm{J}$. 1990;267:431-9.

3. Filali-Mouhim A, Audette M, St-Louis M, Thauvette L, Denoroy L, Penin F, Chen X, Rouleau N, Le Caer JP, Rossier J, Potier M, Le Maire M. Lysozyme fragmentation induced by $c$-radiolysis. Int J Radiat Biol. 1997;72:63-70.

4. Cho Y, Song KB. Effect of $\gamma$-irradiation on the molecular properties of bovine serum albumin and $\beta$-lactoglobulin. $\mathbf{J}$ Biochem Mol Biol. 2000;33:133-7.

5. Lee Y, Song KB. Effect of $\gamma$-irradiation on the molecular properties of myoglobin. J Biochem Mol Biol. 2002;35:590-4.

6. Cieśla K, Salmieri S, Lacroix M, Le Tien C. Gamma irradiation influence on physical properties of milk proteins. Radiat Phys Chem. 2004;71:93-7.

7. Abu JO, Müller K, Duodu KG, Minnaar A. Gamma irradiation of cowpea (Vigna unguiculata L. Walp) flours and pastes: Effects on functional, thermal and molecular properties of isolated proteins. Food Chem. 2006;95:138-47.

8. Terryn H, Maquille A, Houée-Levin C, Tilquin B. Irradiation of human insulin in aqueous solution, first step towards radiosterilization. Int J Pharm. 2007;343:4-11.

9. Oliveira CLP, de la Hoz L, Silva JC, Torriani IL, Netto FM. Effects of gamma radiation on $\beta$-lactoglobulin: oligomerization and aggregation. Biopolym. 2007;85:284-94.

10. de la Hoz L, Netto FM. Structural modifications of $\beta$-lactoglobulin subjected to gamma radiation. Int Dairy J. 2008;18:1126-32.

11. Li XY, Lu Z, Zhang YC, et al. Enhancing effect of low dose radiation on the proliferative activity of thymocytes in mice. J Radiat Res Radiat Process. 1994;12:124-6.

12. Dobrzyński L, Trojanowski W. Selected aspects of human radiobiology (in Polish). Dział Szkolenia i Doradztwa Instytutu Problemów Jądrowych im. A. Sołtana, Świerk, raport 15; 2002.

13. Wolff $\mathrm{S}$. The adaptive response in radiobiology: evolving insights and implications. Environ Health Perspect. 1998;106:277-83.

14. Redpath JL, Antoniono RJ. Induction of an adaptive response against spontaneous neoplastic transformation in vitro by lowdose gamma radiation. Radiat Res. 1998;149:517-20.
15. Redpath JL, Liang D, Taylor TH, Christie C, Elmore E. The shape of the dose-response curve for radiation-induced neoplastic transformation in vitro: evidence for an adaptive response against neoplastic transformation at low doses of low-LET radiation. Radiat Res. 2001;156:700-7.

16. Liu S-Z. Cellular and molecular changes induced by low- versus high-dose radiation. Int Congr Ser. 2002;1225:179-88.

17. Brooks AL. Developing a scientific basis for radiation risk estimates: major goal of the DOE Low Dose Radiation Research Program. Int Congr Ser. 2003;1258:287-95.

18. Widłak P, Pietrowska M, Wojtkiewicz K, Rutkowski T, et al. Radiation-related changes in serum proteome profiles detected by mass spectrometry in blood of patients treated with radiotherapy due to larynx cancer. J Radiat Res. 2011;52:575-81.

19. Rutkowski T, Wygoda A, Pietrowska M, Polańska J, et al. Radiotherapy-induced changes in serum proteome in patients with head and neck cancer; correlation with radiation doses given to differ tissue volumes. Book of abstracts 14th international congress of radiation research, POS34-05, August 28th-September 1st Warsaw; 2011. p. 295.

20. Lörinczy D, editor. Thermal analysis in medical application. Akadémiai Kiadó: Budapest; 2011.

21. Moezzi M, Fekecs T, Zpf I, Ferencz A, Lőrinczy D. Differential scanning calorimetry (DSC) analysis of human plasma in different psoriasis stages. J Therm Anal Calorim. 2012. pp. 1-4. doi:10.1007/s10973-012-2468-2.

22. Cieśla K, Roos Y, Głuszewski W. Denaturation processes in gamma irradiated proteins studied by differential scanning calorimetry. Radiat Phys Chem. 2000;58:233-43.

23. Khan FM. Treatment planning in radiation oncology. 2nd edition. New York: Lippincott Williams \&Wilkins; 2007.

24. Khleif S. Tumor immunology and cancer vaccines. Hingham: Kluwer Academic Publishers; 2005. ISBN 1-4020-8119-7.

25. van Dyk J. et al. The physical aspects of total and half body photon irradiation. AAPM Report No. 17; 1986.

26. Andreo P, Burns DT, Hohlfeld K, Huq MS, Kanai T, Laitano F, Smyth VG, Vynckier S. Absorbed dose determination in external beam radiotherapy: an international code of practice for dosimetry based on standards of absorbed dose to water. Technical Report Series No. 398 (TRS-398). Vienna: IAEA; 2004. p. 61.

27. Sheikh-Bagheri D, Rogers DWO. Monte Carlo calculation of nine megavoltage photon beam spectra using the BEAM code. Med Phys. 2002;29:391-402.

28. Michnik A, Drzazga Z. Thermal denaturation of mixtures of human serum proteins DSC study. J Therm Anal Calorim. 2010; 101:513-8

29. Sturtevant JM. Heat capacity and entropy changes in processes involving proteins. Proc Natl Acad Sci USA. 1977;74:2236-40.

30. Cooper A. Microcalorimetry of heat capacity and volumetric changes in biomolecular interactions-the link to solvation? J Therm Anal Calorim. 2011;104:69-73.

31. Cooper A. Heat capacity effects in protein folding and ligand binding: a re-evaluation of the role of water in biomolecular thermodynamics. Biophys Chem. 2005;115:89-97.

32. Privalov PL. Thermodynamics of protein folding. J Chem Thermodyn. 1997;29:447-74.

33. Rogoliński J, Konopacka M, Ślosarek K, Rusin A. Effect of dose rate on response of cells irradiated during radiotherapy. Book of abstracts 14th international congress of radiation research, POS39-21, August 28th-September 1st Warsaw; 2011. p. 324. 